\title{
An Empirical Study on English Participle Acquisition of the Chinese Arts Majors
}

\author{
Ying Cao \\ School of Applied English Studies, Shandong University of Finance and Economics, Jinan, China
}

\begin{abstract}
The author conducted a study on the participle acquisition by the Chinese art majors. The results indicate that English proficiency does not seem to be a factor which determines the correct use of the participles. In this paper, difficulties the Chinese art majors have in acquiring participles are summarized and the major sources responsible for the errors made by the art majors in the use of participles are analyzed. The paper ends up with putting forward some remedial teaching methods and suggestions based on the analysis of the results.
\end{abstract}

Index Terms - English participles, error analysis, error sources, remedial teaching methods

\section{INTRODUCTION}

The process of English learning is a process of creating interlanguage (IL) and developing IL by constantly correcting errors. It is inevitable that English learners on different levels make many different errors in their process of IL development. In terms of the categories of learners' errors, Brown (1982) suggests four distinct stages along the IL continuum. They are random errors, emergent stage of IL, systematic stage and stabilization, which reflect the general trend of IL development.

Analyzing errors in the EFL learners' IL is an important method in second language acquisition and sheds much insight on the language pedagogy. Much research was done to study the IL errors of second language learners. However, the study on English participle acquisition by the Chinese art majors is still insufficient, which is significant for the further understanding of their IL characteristics.

For the art majors, most of whom are poorly prepared in English before entering university, acquiring English participle seems to be twice as difficult as the other college majors. When going over either their writing or translation, the author finds that the art majors seldom use participles and seem to try to avoid using them. Most of the students who attempt to use participles always make errors.

However, it is essential for the art majors to acquire English for the development of Chinese art and cultural industry. In the context of globalization, as the backbone, the art students will become the leading participants to propel the interaction of Chinese and Foreign art and culture and accelerate the progress of art and culture blend in the near future.

Though there have been many studies on English grammatical errors made by Chinese EFL learners, it's a pity that the study on the errors committed by the college art majors in their use of English participles is yet to be conducted.

All this arouses the author's great interest in probing the underlying reasons of their avoidance and what teachers in the art colleges can do to help change the situation.

\section{Formation AND MEANing of PARTiciples}

A participle can be a verb, which is a derivative of a non-finite verb, or share properties with adjectives, adverbs and nouns.

The term "participle" is generally restricted to non-finite forms of a verb other than the infinitive; in English, it is often classified into present and past forms, or into "-ing" and "-ed" forms (Crystal, 1992).

\section{A. Present Participle}

The -ing form is called the present participle which can also be called variously the active participle, imperfect participle, or progressive participle. In present-day English, gerund and present participle are derived from one and the same linguistic form---the -ing. In principle, there is nothing surprising about this form being able to perform the same grammatical functions as a noun or an adjective in some of its uses, nor is it surprising that it should be able to perform other functions as well (Duffley, 2006).

The term "present participle" is now used to include the gerund, so the term "gerund-participle", which is adopted from Cambridge Grammar of the English Language (Huddleston and Pullum, 2002), is also used. The English gerundparticiple is a stable form, but it has no stable meaning (Patrick J. Duffley, 2006).

According to John M. Lawler, the form of -ing is used in the following English constructions:

1. as the next verb form after the "be" of the continuous or progressive aspect.

2. in adjectival clauses modifying noun phrases, which is equivalent to a relative clause constructions. 
3. as the head of an adverbial clause, often introduced by a subordinating conjunction, and usually without a subject; it can take "have" to indicate it happened in the past.

4. as the main verb in a "gerund" complement, i.e, a subordinate noun clause functioning as subject, direct object or predicative of a higher clause. The complement clause is a noun phrase, but the gerund itself is a verb phrase. In other words, the gerund form is a real (though non-finite) verb, and it can take a subject (in the possessive case) and an object (in the objective), and can be modified by adverbs, etc.

E.g.: Our work is serving the people.

5. as a true noun, derived from a verb. It is a "verbal noun". This is usually called the gerund or "-ing" nominalizer, and it can't take an object. Besides, a true noun can take a definite article, whereas a verb can not.

For the convenience of the current study, the author uses the term "present participle" to refer to the first three usages of this verb form "-ing" and "gerund" to the last two usages.

\section{B. Past Participle}

The other variety of English participles is called the past participle which does not have a consistent ending, and it is usually identical to the regular verb's past tense form which ends in -ed, and the past participles of irregular verbs, however, vary considerably. The past participle is used in forming the perfective aspect and the passive voice. It can also be called variously the passive participle or perfect participle.

The past participle which can be used in both active and passive voices is often used in the following English constructions:

1. forming the perfect tense.

2. forming the passive voice.

3. modifying a noun, with active sense: the fallen leaves.

4. modifying a noun, with passive sense: the injured worker.

5. modifying a verb or sentence, with passive sense: Given more time, we could have done it better.

\section{Dangling Participles}

Participles or participial clauses may always appear at the beginning or the end of a sentence, and a participial clause is usually attached to its subject, as in "Absorbed in computer games (participial clause), Tonny (subject) didn't notice my arriving (object)." However, when the participial clause attaches itself to a word other than the one intended, or with no particular word at all, the clause is seemingly "hanging" on nothing or on an entirely inappropriate noun, and "dangles" in mid-air, attaching to no named person or thing. It thus becomes a dangling participle, which is an error in sentence structure. E.g. "Absorbed in computer games, the computer crashed." In the sentence, the past participle "absorbed" has not its own subject, and the participial phrase "absorbed in computer games" seems to connect to "the computer." Actually, "the computer" is not itself "absorbed in computer games." Upon reflection, there is another unmentioned subject, a person who was playing the computer games, to which the participle really should connect. Grammarians say that such a sentence contains a "dangling participle."

There is another kind of example:

He recognized the face of his neighbor peering out the door into the night.

The placement of the participial clause "peering out the door into the night" causes ambiguity, and makes it sound as if his neighbor peered out the door into the night. More correctly, it can be written as, "Peering out the door into the night, he recognized the face of his neighbor."

Although dangling participles originate from the error of grammar, many dangling constructions have already been viewed as fixed structures without restriction of the subject in main clause. E.g.: Considering..., Judging from..., According to..., Generally speaking.

\section{MethodOLOGY}

The methodology section first presents the research questions. It then introduces the background of the participants and the instruments employed in present research. The introduction is followed by the procedure of data collection.

To strengthen the reliability of the data, and make this study as objective as possible, both qualitative and quantitative research methods were employed. According to the research questions, a participle test was designed and related software was used to aid the analysis.

\section{A. Research Questions}

The current research focuses on the acquisition of English participles by Chinese art majors as well as discovering their IL features in the acquisitional development of participles.

In order to have a comparatively comprehensive understanding of the errors the art majors commit and their knowledge and uses of the participles, the following four research questions will be addressed:

1. How well do the art majors master the English participle?

2. Does the English proficiency determine the acquisition of the participles by the art majors?

3. What are the difficulties for the art majors in the process of using participles?

4. What causes the errors committed by the art majors in the use of participles? 


\section{B. Participants}

Eighty college art majors participated in the present study. It involved two different learner groups. For each group there were 40 subjects. All the subjects were the students from College of Arts and Culture (CAC) in Shandong University of Arts. They majored in broadcasting and TV director (BTD), public utilities management (PUM), management of cultural and art industry (MCAI), movie and TV arts (MTA) and fine arts (FA) respectively. The five majors in each grade were admitted by CAC with exactly the same entrance requirements, and after entering the university, they were taught by the same English teachers and attended the same English curricula during their freshman and sophomore period. The subjects of each group were taken out at random from the participle-test-taking participants in the five majors. Before entering university, they had learned English as a foreign language through formal instruction for 6 years in China. They all had finished a comprehensive study of English Grammar including English participles before this empirical study. According to the years of their English study, 80 subjects were divided into the following two groups.

Group One. The subjects from Group one were composed of 40 freshmen of SUA. When tested, they were busy with their second semester's study in the freshman period. The average age of Group one was 19. They were all admitted by $\mathrm{CAC}$ on condition that their scores of the entrance examination to the college were above 510 and the scores of English couldn't be lower than 80 (the full mark was 150). These students hadn't taken College English Test Band 4 and all of them had been studying College English for more than half a year. Besides, the subjects of this group came from different parts of Shandong province.

Group Two. The subjects in Group two were 40 junior students from CAC of SUA. They were from the 5 majors mentioned above. All of the 40 subjects took the CET-4 and passed it. Among them, 4 subjects got the scores ranging from 500 to 550, 8 subjects from 450 to 500, and the others (28 subjects in total) from 425 to 450 . Two of them were holders of College English Test Band 6 certificate. The subjects of this group had studied English for more than eight years and a half before the empirical study. The average age of Group two was 22. In addition, all the subjects were from different parts of Shandong province.

TABLE 3.1:

PROFILE OF SUBJECTS PARTICIPATING IN THE TEST

\begin{tabular}{|l|l|l|l|}
\hline \multicolumn{2}{|l|}{} & Group 1 & Group 2 \\
\hline Average Years of Learning English & 6.5 & 8.5 \\
\hline Average Age & BTD & 19 & 22 \\
\hline \multirow{4}{*}{ Major } & PUM & 7 & 8 \\
\cline { 2 - 5 } & MCAI & 16 & 8 \\
\cline { 2 - 5 } & MTA & 5 & 6 \\
\cline { 2 - 5 } & FA & 4 & 5 \\
\hline
\end{tabular}

The researcher and the teachers involved put the subjects in a normal and authentic environment so that they haven't realized and recognized their identity in this experiment. Additionally, neither participating groups received any special training on the use of English participles before the test.

\section{Instruments}

The instruments used in the study were a participle test and an interview. The data collection was manipulated by English teachers in SUA. The author explained to them in detail the purpose and requirements for allocating and collecting the participle tests and ensured their full cooperation. All the participants were required to finish the participle test in 35 minutes.

While the data were being elicited, care was taken so that the subjects would not intentionally pay attention to the grammatical item the author intended to test. Besides, instructions were given by the teachers in Chinese to ensure that the subjects completely understood the requirements.

The SPSS software was used for doing statistical analysis.

1. Participle test

Participle test, which is designed to test the essential use of English participles, consists of three parts: choice test, blank filling and a Chinese-English translation judgment test.

The participle testing items involve voice, aspect, the transformed part of speech and the like.

In order to guarantee the validity of the test, all words used in the participle test are from high school vocabulary list, and there is no difficulty for all the participants in terms of vocabulary in the test. Therefore, the students can't be distracted by the words they do not know and can concentrate their attention on the participle test items.

All the questions in the test are from the examination questions in CET-4 and the participle-specialized exercises for CET-4. Two experienced professors who had taught English for more than 15 years checked every question to ensure that each question had but only one correct and optimal answer.

2. Interview

Interviews were conducted after the participle tests were scored. Among the 80 subjects, we only chose 10 subjects who made more errors in the participle test in each group as the representatives, since it was too time-consuming to 
interview every subject involved. The subjects were interviewed one by one by their English teacher and the author, and they were asked questions such as "Do you often use participles in your translation or writing?" "Did you fail to use participles just because you were afraid of making mistakes or because they seldom came to your mind while writing in English?" "Do you know the expression 'see sth. done'? And what does it mean?" "Under what kind of circumstance will you use present participle?" "Can you tell me what situation calls for use of past participle?" "Do you know what determine the choice making between the present participle and the past participle in the participles as attribute, as predicative, as complement and in the participial phrase as adverbial?" "During the participle test, did you always translate the English questions into Chinese to help make a choice or judgment?" "Does the Chinese marker “被” remind you of using past participle?" "Can you name the other Chinese markers which can remind you of using past participle?" "Do you know the difference between gerunds and present participles?" "Do you know how to use the perfective aspect of the participle?"

3. Software

SPSS statistics 17.0 was used for doing statistical analysis. The independent samples t-test was used to compare the error frequencies and find out whether there was a significant difference in the language achievement between the two learner groups.

\section{RESULTS}

\section{A. Error Rates under Each Category}

This part primarily exhibits distribution of error rates according to the types of participles concerning the two subject groups. All the English participles in question are classified into the six types: participles as attribute, participles as predicative, participles as adverbial, participles as complement, gerunds and dangling participles. And progressive aspect and passive voice are also involved. With the accuracy order of the use of participles tested, the researcher hopes to figure out the acquisition of the six types of participles by the Chinese art majors.

The number of errors and the error rates of each type are illustrated separately in the following columns.

TABLE 4.1:

ERROR RATES OF PARTICIPLES UNDER EACH CATEGORY

\begin{tabular}{|c|c|c|c|c|c|}
\hline \multicolumn{2}{|c|}{ Types of Participles } & \multicolumn{2}{|c|}{$\begin{array}{l}\text { Number of Errors in Participle } \\
\text { Use }\end{array}$} & \multirow{2}{*}{$\begin{array}{l}\text { Number of } \\
\text { Participles } \\
280 \\
\end{array}$} & \multirow{2}{*}{$\frac{\text { Error Rates }}{30.7 \%}$} \\
\hline Participle as & Attribute & \multirow{10}{*}{$\begin{array}{l}\text { Group } \\
2\end{array}$} & 86 & & \\
\hline Adjective & Predicative & & 113 & 280 & $40.4 \%$ \\
\hline \multicolumn{2}{|c|}{ Participle as Adverbial } & & 230 & 440 & $52.3 \%$ \\
\hline \multicolumn{2}{|c|}{ Participle as Complement } & & 83 & 360 & $23.1 \%$ \\
\hline \multicolumn{2}{|c|}{ Gerund } & & 168 & 440 & $38.2 \%$ \\
\hline \multicolumn{2}{|c|}{ Dangling Participle } & & 68 & 160 & $42.5 \%$ \\
\hline \multicolumn{2}{|c|}{ Passive Voice } & & 3 & 40 & $7.5 \%$ \\
\hline \multicolumn{2}{|c|}{ Progressive Aspect } & & 0 & 40 & 0 \\
\hline \multicolumn{2}{|c|}{$\begin{array}{l}\text { Mixture of Progressive Aspect \& Passive } \\
\text { voice }\end{array}$} & & 8 & 40 & $20 \%$ \\
\hline \multicolumn{2}{|l|}{ Others } & & 22 & 40 & $55 \%$ \\
\hline & & Total & 781 & 2120 & $36.8 \%$ \\
\hline \multirow{2}{*}{$\begin{array}{l}\text { Participle as } \\
\text { Adjective }\end{array}$} & Attribute & & 79 & 280 & $28.2 \%$ \\
\hline & Predicative & & 129 & 280 & $46.1 \%$ \\
\hline \multicolumn{2}{|c|}{ Participle as Adverbial } & & 243 & 440 & $55.2 \%$ \\
\hline \multicolumn{2}{|c|}{ Participle as Complement } & & 71 & 360 & $19.7 \%$ \\
\hline \multicolumn{2}{|c|}{ Gerund } & Group & 156 & 440 & $35.5 \%$ \\
\hline \multicolumn{2}{|c|}{ Dangling Participle } & 1 & 79 & 160 & $49.4 \%$ \\
\hline \multicolumn{2}{|c|}{ Passive Voice } & & 0 & 40 & 0 \\
\hline \multicolumn{2}{|c|}{ Progressive Aspect } & & 0 & 40 & 0 \\
\hline \multicolumn{2}{|c|}{$\begin{array}{l}\text { Mixture of Progressive Aspect \& Passive } \\
\text { voice }\end{array}$} & & 2 & 40 & $5 \%$ \\
\hline \multicolumn{2}{|l|}{ Others } & & 29 & 40 & $72.5 \%$ \\
\hline \multicolumn{2}{|l|}{ Total } & & 788 & 2120 & $37.2 \%$ \\
\hline
\end{tabular}

For the convenience of comparison and discussion later in the paper, it is proper here to illustrate the error rates of each type of participles in two groups by figures, which clearly reveals the participle acquisition by the art majors with different English competence. 


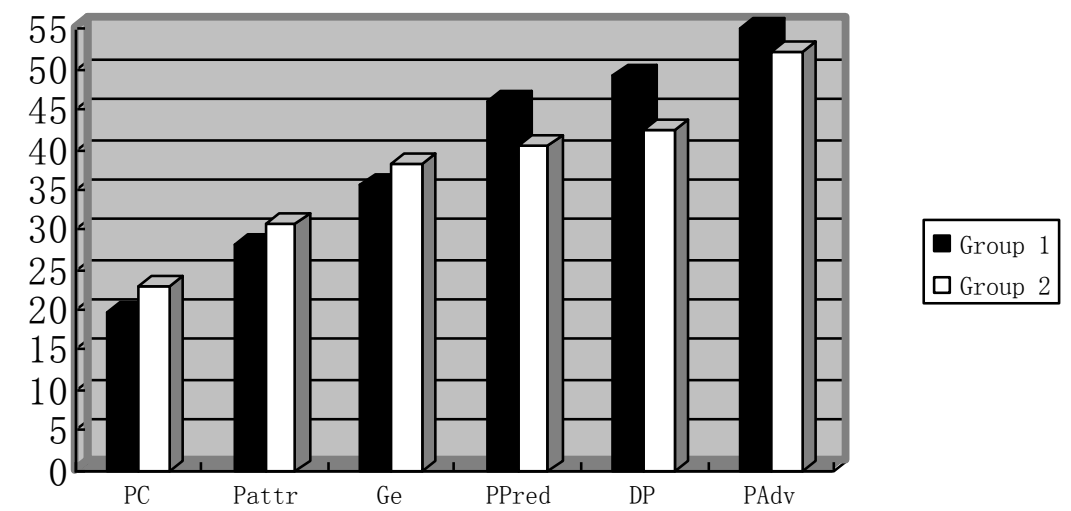

PC: Participles as Complement

PAttr: Participles as Attribute Ge: Gerunds PPred: Participles as Predicative DP: Dangling Participles

PAdv: Participles as Adverbial Figure 4.1: Error Rates of Participles under Each Category

\section{B. Error Rate Comparison between Two Learner Groups}

For the purpose of figuring out whether there was significant difference in the English participle acquisition between the lower grade group and the upper grade group on the basis of the error rates calculated above, independent samples T-test was used.

TABLE 4.2:

RESULTS OF GROUP STATISTICS

Group Statistics

\begin{tabular}{|c|c|c|c|c|}
\hline & Group & $\mathrm{N}$ & Mean & Std Deviation \\
\hline \multirow[t]{2}{*}{ PAttr } & group 1 & 7 & 28.2143 & 21.10067 \\
\hline & group 2 & 7 & 30.7143 & 16.56517 \\
\hline \multirow[t]{2}{*}{ PPred } & group 1 & 7 & 46.0714 & 28.97043 \\
\hline & group 2 & 7 & 36.0714 & 22.72376 \\
\hline \multirow[t]{2}{*}{ PC } & group 1 & 9 & 19.7222 & 21.70269 \\
\hline & group 2 & 9 & 23.0556 & 12.16923 \\
\hline \multirow[t]{2}{*}{ Gerund } & group 1 & 11 & 35.4091 & 23.52851 \\
\hline & group 2 & 11 & 38.1818 & 23.79840 \\
\hline \multirow[t]{2}{*}{ DP } & group 1 & 4 & 49.3750 & 32.16980 \\
\hline & group 2 & 4 & 42.5000 & 35.76544 \\
\hline \multirow[t]{2}{*}{ PAdv } & group 1 & 11 & 50.4545 & 19.51980 \\
\hline & group 2 & 11 & 47.2727 & 16.89876 \\
\hline \multirow[t]{2}{*}{ Total } & group 1 & & 39.7 & \\
\hline & group 2 & & 37.3 & \\
\hline
\end{tabular}

PAttr: Participles as Attribute

PC: Participles as Complement

DP: Dangling Participles

PPred: Participles as Predicative

Ge: Gerunds

PAdv: Participles as Adverbial 
TABLE 4.3:

RESULTS OF INDEPENDENT SAMPLES T-TEST

Independent Samples T-Test

\begin{tabular}{|c|c|c|c|c|c|c|c|}
\hline \\
\hline & & \multicolumn{2}{|c|}{ Levene's Test for Equality of Variances } & \multicolumn{4}{|c|}{ T-test for Equality of Means } \\
\hline & & $\mathrm{F}$ & Sig. & $\mathrm{t}$ & df & Sig. (two-tailed) & Mean Differences \\
\hline \multirow[t]{2}{*}{ PAttr } & Equal variances assumed & .097 & .761 & -.247 & 12 & .809 & -2.50000 \\
\hline & $\begin{array}{l}\text { Equal variances not } \\
\text { assumed }\end{array}$ & & & -.247 & 11.360 & .810 & -2.50000 \\
\hline \multirow[t]{2}{*}{ PPred } & Equal variances assumed & 2.223 & .162 & .719 & 12 & .486 & 10.00000 \\
\hline & $\begin{array}{l}\text { Equal variances not } \\
\text { assumed }\end{array}$ & & & .719 & 11.356 & .487 & 10.00000 \\
\hline \multirow[t]{2}{*}{ PC } & Equal variances assumed & 1.695 & .211 & -.402 & 16 & .693 & -3.33333 \\
\hline & $\begin{array}{l}\text { Equal variances not } \\
\text { assumed }\end{array}$ & & & -.402 & 12.578 & .695 & -3.33333 \\
\hline \multirow[t]{2}{*}{ Gerund } & Equal variances assumed & .017 & .896 & -.275 & 20 & .786 & -2.77273 \\
\hline & $\begin{array}{l}\text { Equal variances not } \\
\text { assumed }\end{array}$ & & & -.275 & 19.997 & .786 & -2.77273 \\
\hline \multirow[t]{2}{*}{ DP } & Equal variances assumed & .182 & .684 & .286 & 6 & .785 & 6.87500 \\
\hline & $\begin{array}{l}\text { Equal variances not } \\
\text { assumed }\end{array}$ & & & .286 & 5.934 & .785 & 6.87500 \\
\hline \multirow[t]{2}{*}{ PAdv } & Equal variances assumed & .091 & .767 & .409 & 20 & .687 & 3.1818 \\
\hline & $\begin{array}{l}\text { Equal variances not } \\
\text { assumed }\end{array}$ & & & .409 & 19.598 & .687 & 3.1818 \\
\hline & $\begin{array}{r}\text { PAttr: Pa } \\
\text { DP: Dan }\end{array}$ & $\begin{array}{l}\text { Prticipl } \\
\text { PC: } \\
\text { ngling }\end{array}$ & $\begin{array}{l}\text { tribute } \\
\text { les as Complement } \\
\text { les }\end{array}$ & $\mathrm{P}$ & $\begin{array}{l}\text { Participl } \\
\text { Ge: Ger } \\
\text { Participl }\end{array}$ & $\begin{array}{l}\text { is Predicative } \\
\text { ds } \\
\text { as Adverbial }\end{array}$ & \\
\hline
\end{tabular}

In the first place, according to table 4.3, for the participles as attribute, participles as predicative, participles as complement, gerunds, dangling participles and participles as adverbial, in the Levene's test for equality of variances, all of their $\mathrm{P}$ values are much higher than 0.05 , so their variances are equal. Furthermore, in the T-test for equality of means, their $\mathrm{P}$ values, which correspond to the equal variances, are showed to be much higher than 0.01 , and thus the conclusion can be drawn that there is no significant difference in the use of English participles between the two experimental groups under the six types.

Secondly, the result of independent samples test exhibits that the art majors do not have a good mastery of English participles, because the overall mean of the error rates of the two groups is 38.5. And the overall mean of the lower grade group and the upper grade group is 39.7 and 37.3 respectively.

According to the table 4.2, the mean value of the error rates of participles as adverbial is the highest, dangling participles, participles as predicative, gerunds, and participles as attribute in turn, and the mean value of the participles as complement is lowest. Namely, the subjects in the current study master participles as complement best, participles as attribute, gerunds, participles as predicative and dangling participles in turn, and they have a worst grasp of participles as adverbial.

According to the mean differences illustrated in table 4.3, compared with the upper grade group (the second group), the lower grade group (the first group) have a better mastery of participles as complement (-3.33333), gerunds ($2.77273)$ and participles as attribute $(-2.50000)$ but make more errors in participles as predicative (10.00000), dangling participles (6.87500) and participles as adverbial (3.1818).

\section{MAJOR FINDINGS}

On the basis of the analysis and elaboration of the data, the following findings can be presented:

1. Through the analysis of the data collected, a conclusion can be drawn that English participle, as a unique English grammatical item, is a very difficult grammatical item for the art majors to acquire and their knowledge of participles is incomplete. The 4 major types of errors committed by the art majors are overlooking the logical subject of participles, wrong use of absolute construction, wrong use of gerunds, failure in use of perfective aspect of the participle and dangling constructions.

2. With the aid of independent samples T-test, it is discovered that for the art majors, English proficiency does not seem to be a factor which determines the correct use of the participles. Comparatively, the upper grader (subjects in the second group) has a better mastery of participles as predicative, dangling participles and participles as adverbial than the lower grader (subjects in the first group), but they are weaker in gerunds, participles as attribute and participles as complement.

3. The results show that for the art students, the correct rate of using participles as complement (78.7\%) is the highest, participles as attribute $(70.5 \%)$, gerunds $(63.3 \%)$, participles as predicative $(57 \%)$ and dangling participles $(54.3 \%)$ in turn; the correct rate of using participles as adverbial $(46.25 \%)$ is the lowest. 
4. For the art majors, they have difficulty in acquiring (1) absolute construction, (2) dangling participles, (3) perfective aspect of participles as adverbial, (4) the past participle of the intransitive verb, which is used as adjective to indicate the completion of the action, (5) the compound structure of gerund; and have some trouble in discriminating the usage of participles from that of the infinitive.

5. From the high error frequencies and the types of error they committed, it is evident that the IL system of the art majors is inadequate and their grammatical system of English is not yet stabilized. The major sources responsible for the errors made by the art students in the use of participles are: (1) negative transfer (literal translation), (2) overgeneralization (false analogy), (3) transfer of training (hypercorrection) and (4) failure in rule application. Among them, apart from negative transfer which leads to the interlingual errors, the other three all cause intralingual errors. In the case of the intralingual errors, the transfer of training plays a larger role. To a certain degree, overgeneralization sometimes occurs after the art students receive overcorrection or excessive drills on some grammatical items.

\section{Pedagogical Suggestions}

In this part, pedagogical implications of the findings will be discussed.

Initially, the errors the college art majors commit indicate the levels of their English proficiency or their IL competence. Most of the art majors know some rules of English participles but fail to apply them correctly. According to Corder (1967), the learners in this stage need further internalization of target language rules.

Secondly, after two-year-college-English study, the art majors make a little improvement in their participle use. It is advisable that the English teachers in the colleges of arts should dedicate some of their energy to the grammar teaching and help the art majors to master this unique and important grammatical item.

In reality, grammar teaching has experienced many ups and downs in the process of English teaching. To some extent, grammar teaching has been questioned, but traditional opinions all regard grammar teaching as an indispensable part in English language teaching. It is suggested in the current study that English grammar should be taught in colleges, especially in the art colleges.

In resent years, quite a large number of instructors in colleges have devoted themselves to the improvement of their students' English proficiency, especially their listening and speaking abilities. They lay much emphasis on the English communication and attach less importance to the grammar teaching. Consequently, many students in the art colleges today have an awful mastery of the basic knowledge of English grammar. They aren't able to comprehend the passage well or to write grammatical sentences. Many of the compositions they write are unreadable. No wonder the result of the current study shows that the art majors' knowledge of participles is incomplete and there is no significant difference between the art majors of lower grade and those of upper grade in the acquisition of English participles---a very important grammatical item.

Moreover, students nowadays are faced with different kinds of English examinations to test their language abilities. For the students in the universities of arts, they are also required to take the College English Test Bank 4 and Bank 6 . In the past, the CET-4 had a question type---vocabulary and structure, which was designed exclusively to test the students' grammar. In order to pass the examination, the art majors have to do the specialized exercises on grammar and learn it attentively. However, this question type is cancelled now. In the CET-4 in June in 2009, which all the subjects of the second group in current study participated in, there is no one question designed exclusively for testing the usage of English participles. Moreover, more than half of the art students can pass the CET-4 without knowing the participles well. Consequently, the instructors in the colleges of art ignore the purposeful training on this grammatical item and the art majors also pay little attention to it.

As we all know, the language abilities are composed of both knowledge and skills of language, and it is impossible to virtually acquire a language if we ignore its grammar study. In other words, the abilities of using English, both in English writing and in English speaking, will be efficiently improved by a good mastery of its grammar. Therefore, grammar teaching in the art colleges is an indispensable procedure in the English teaching, and English teachers should reconsider the role of grammar and come up with appropriate and practical approaches to help change the situation.

Thirdly, the Chinese art majors still rely unconsciously on their mother tongue and always adopt the word-for-word translation strategy while using English participles, and it thus requires that English teachers in the colleges of arts should make the students aware that Chinese and English are quite different in the verb systems, train them to think in English and give them effective instructions in their English learning strategy. Besides, intralingual errors are more responsible for the bad performance in the art students' participle use, and among the intralingual errors, transfer of training plays a larger role. Therefore, a proposal is put forward that the English teachers should encourage more frequent and practical use of participles in the art majors' translations, writings and speaking rather than overcorrect their errors or train them to do the excessive exercises on a specific rule of the participles.

\section{ACKNOWLEDGEMENT}

My paper cannot be completed without tremendous encouragement and help of so many people. 
I am extremely grateful, first of all, to my supervisor, Professor Ma Wen, who enlightened me on the subject of this paper, and has provided me with valuable advice and constructive suggestions throughout the whole process of my paper writing. Without his insightful guidance, I would not have been able to accomplish this paper.

Secondly, I am indebted to the teachers from College of Arts and Culture in Shandong University of Arts who have kindly co-operated with me to finish the data collection job. But for their help, I could not conduct my research smoothly.

\section{REFERENCES}

[1] Brown, H. D. (1982). Principles of Language Learning and Teaching. New York: Prentice Hall Regents.

[2] Corder, S. P. (1967). The Significance of Learners' Errors. International Review of Applied Linguistics. Oxford: Oxford University Press.

[3] Crystal, D. (1992). International Encyclopedia of Linguistics. Oxford: Oxford University Press

[4] Duffley, P. J. (2006). The English Gerund-Participle: A Comparison with the Infinitive. New York: Peter Lang Publishing, Inc.

[5] Huddleston, R. \& Pullum, G. K. (2002). Cambridge Grammar of the English Language. New York: Cambridge University Press.

[6] http://www-personal.umich.edu/ jlawler/aue (accessed 29/7/2011).

Ying Cao was born in Jinan, China in 1980. She received her MA in linguistics from School of Foreign Languages and Literature, Shandong University, Jinan, China in 2010.

She is currently an instructor in the School of Applied English Studies, Shandong University of Finance and Economics, Jinan, China. Her research interests are second language acquisition and applied linguistics. 